\title{
LAUR-92-4261
}

January 1993

INTEGRATED VERIFICATION EXPERIMENT DATA COLLECTED AS PART OF THE LOS ALAMOS NATIONAL LABORATORY'S SOURCE REGION PROGRAM

\section{APPENDIX D:}

\section{IONOSPHERIC MEASUREMENTS FOR IVES}

T. Joseph Fitzgerald, Robert C. Carlos, and Paul E. Argo

\section{LOS ALAMOS SOURCE REGION PROGRAM}

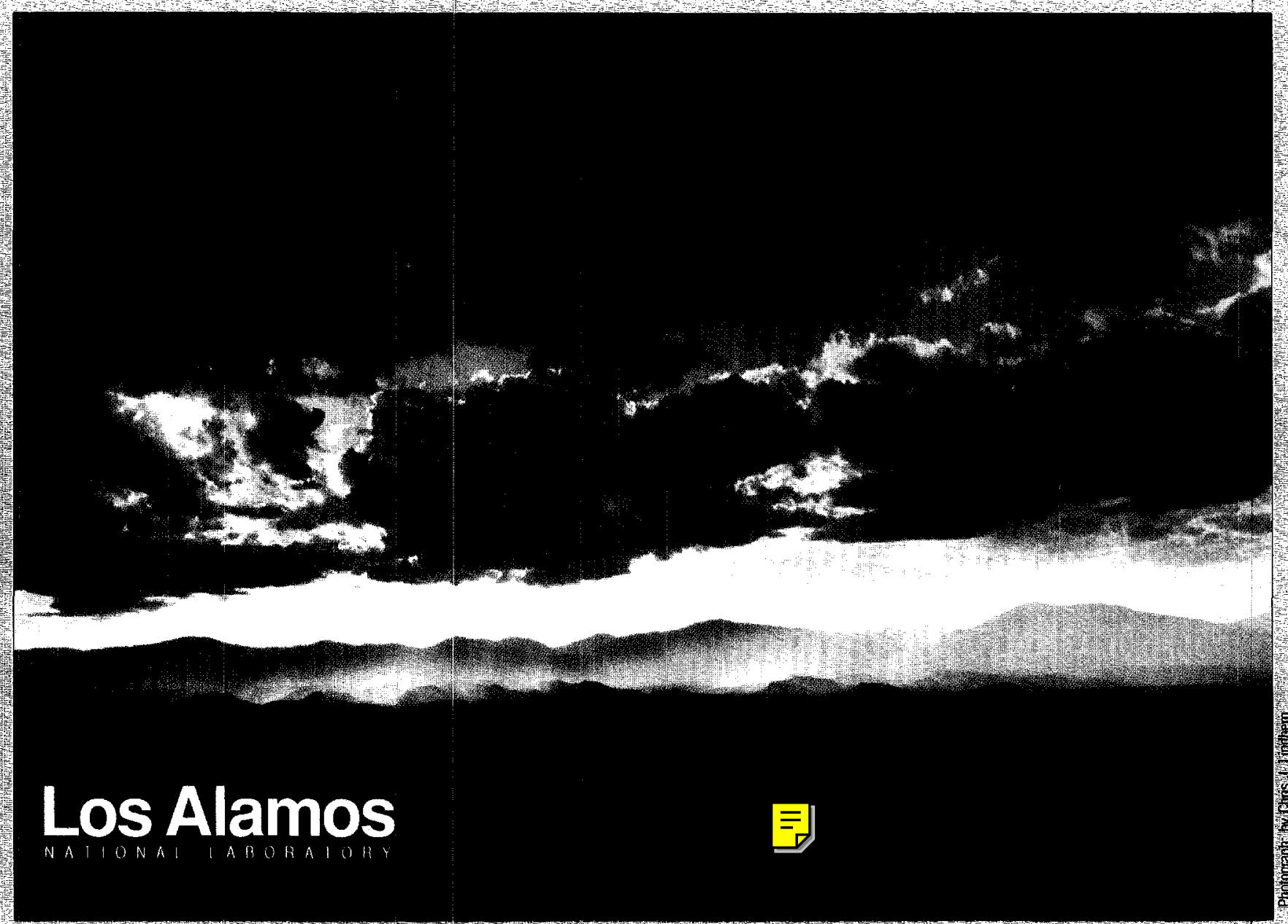


Los Alamos National Laboratory is operated by the University of California for the United States Department of Energy under contract W-7405-ENG-36.

An Affirmative Action/Equal Opportunity Employer

\section{DISCLAIMER}

This report was prepared as an account of work sponsored by an agency of the United States Government. Neither the United States Government nor any agency thereof, nor any of their employees, makes any warranty, express or implied, or assumes any legal liability or responsiblity for the accuracy, completeness, or usefulness of any information, apparatus, product, or process disclosed, or represents that its use would not infringe privately owned rights. Reference herein to any specific commercial product, process, or service by trade name, trademark, manufacturer, or otherwise, does not necessarily constitute or imply its endorsement, recommendation, or favoring by the United States Government or any agency thereof. The views and opinions of authors expressed herein do not necessarily state or reflect those of the United States Government or any agency thereof. 


\title{
INTEGRATED VERIFICATION EXPERIMENT DATA COLLECTED AS PART OF THE LOS ALAMOS NATIONAL LABORATORY'S SOURCE REGION PROGRAM APPENDIX D: \\ IONOSPHERIC MEASUREMENTS OF IVES
}

\author{
T. JOSEPH FITZGERALD \\ ROBERT C. CARLOS \\ PAUL E. ARGO \\ Atmospheric Sciences, SST-7 \\ Los Alamos National Laboratory \\ Los Alamos, New Mexico 87545
}

January 21,1993

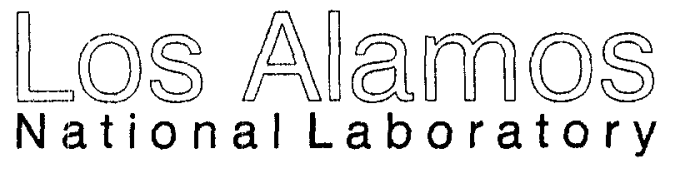




\section{Contents}

Abstract

1 Introduction $\quad 7$

2 Misty Echo 9

3 Texarkana 9

4 Mineral Quarry 9

5 Bexar , 10 


\begin{abstract}
As part of the integrated verification experiments (IVE), we deployed a network of hf ionospheric sounders to detect the effects of acoustic waves generated by surface ground motion following underground nuclear tests at the Nevada Test Site. The network sampled up to four geographic locations in the ionosphere from almost directly overhead of the surface ground zero out to a horizontal range of $60 \mathrm{~km}$. We present sample results for four of the IVEs: Misty Echo, Texarkana, Mineral Quarry, and Bexar.
\end{abstract}




\section{Introduction}

This appendix presents a description of the ionospheric measurements conducted for the integrated verification experiments (IVE) and a sample of the results for the following events: Misty Echo, Texarkana, Mineral Quarry, and Bexar. Because of other commitments ionospheric measurements for the following events could not be obtained: Tulia, Contact, Hornitos, Bullion, and Junction. Experimental difficulties prevented any data acquisition on two events: Amarillo and Metropolis. No ionospheric disturbance was detected for the Ingot event for reasons discussed below. Ionospheric measurements were obtained for several non-IVE events during the same time period but these will not be discussed here.

Ionospheric detection of UGTs relies on the generation of an acoustic wave by surface ground motion following the explosion and propagation of the acoustic wave to high altitudes above $\mathrm{GZ}$ where its interaction with the natural jonospheric plasma produces electron density changes. In the detection technique employed for the IVEs, we broadcast highly stable radio tones in the high frequency band, about $3 \mathrm{MHz}$; the frequency is chosen so that the radio signal is reflected in the ionosphere at an altitude of about $100 \mathrm{~km}$. Any disturbance to the electron density at the reflection level, such as that produced by the acoustic waves following a UGT, will alter the radio signal and thus allows the detection and categorization of the acoustic source.

Our technique is called bistatic radio propagation, that is, a transmitter at one location broadcasts to a receiver at a far enough distance so that direct propagation (ground wave) is highly reduced compared to ionospheric propagation (sky wave). The sensitive region for detecting acoustic disturbances is above the geographic midpoint of the path between transmitter and receiver. For the IVEs we employed two transmitter locations, one at Tonopah Test Range (TTR) and the other at the EPA Farm in Area 15 of the NTS; we also employed two receiver locations, one near Well $5 e$ in Area 5 of the NTS and the other at Indian Springs AFB (ISP). The map in Figure 1 shows that these locations give sensitive regions over Area 19, Area 12, and Area 3 where most Los Alamos events are conducted. Table 1 lists the paths used for the four experiments for which we present results. We detected the high frequency radio signals with Racal $6790 \mathrm{GM}$ receivers operated in $\mathrm{cw}$ mode which produced a low-passed audio signal at a frequency between 20 to $50 \mathrm{~Hz}$ which were digitized and stored. In the analysis presented here, we performed a digital complex demodulation and decimation of the signal to derive time series of the complex amplitudes of the received signals in a $\pm 5 \mathrm{~Hz}$ frequency band. The power spectra of these time series presented below show variations of the detected signal versus frequency relative to the nominal transmitted radio frequency.

In general we broadcasted two frequencies from each transmitter location; the two frequencies were chosen so that they reflected from sufficiently separated altitudes to allow time delay discrimination of the acoustic waves. Moreover, we employed a spatial array of antennas at the receive locations so that we could conduct interferometry and array processing of the disturbances. The arrays are illustrated in Figure 1. 


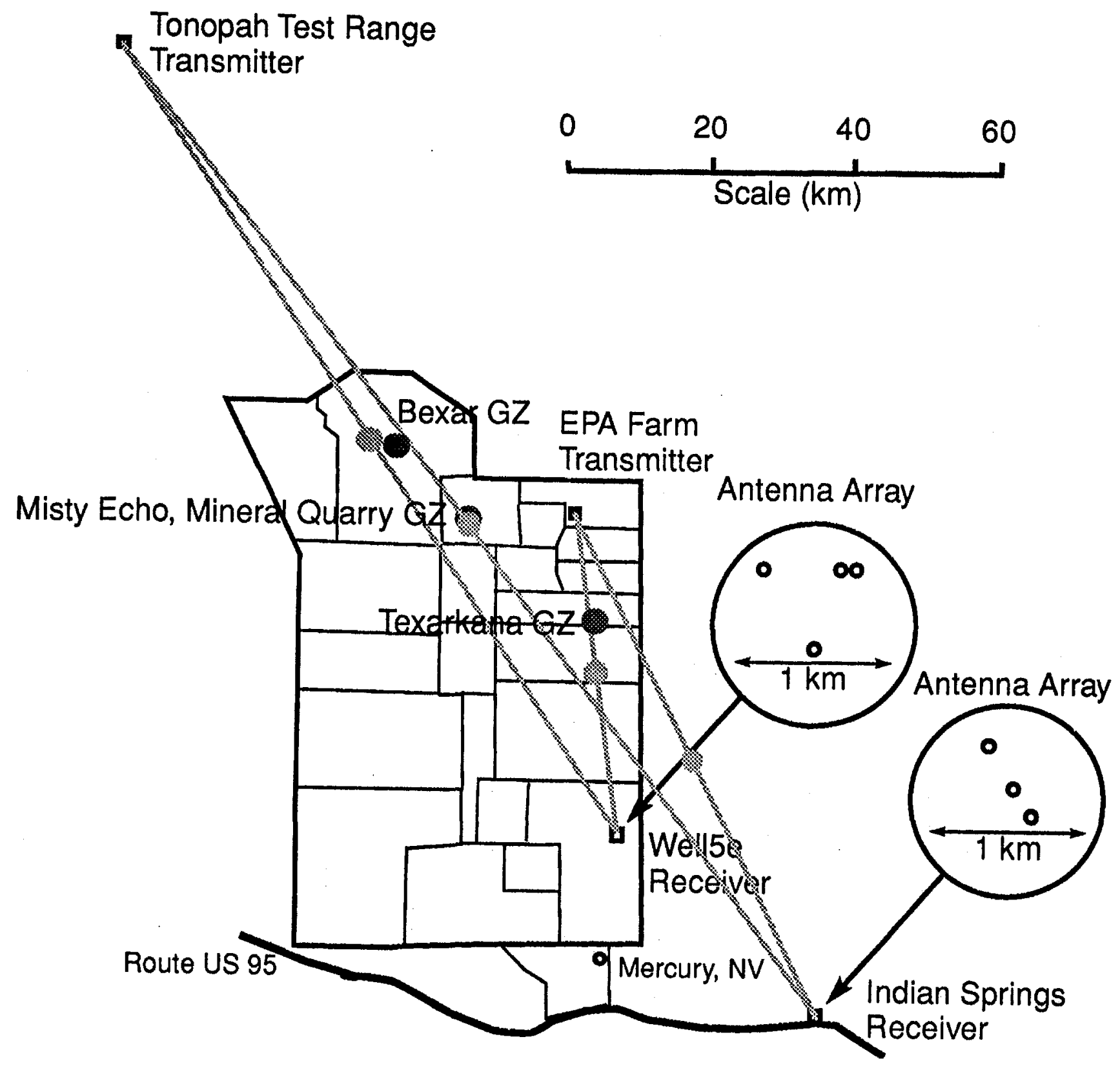

Figure 1: Location of transmit and receive stations used for ionospheric measurements for IVEs. Dark-filled circles indicate locations of surface ground zero; light-filled circles indicate mid-paths between transmitters and receivers. 


\begin{tabular}{|c|c|c|c|c|}
\hline Event & WL5-EPA & WL5-TTR & ISP-EPA & ISP-TTR \\
\hline Misty Echo & & & & $\bullet$ \\
\hline Texarkana & $\bullet$ & & & \\
\hline Mineral Quarry & & & & $\bullet$ \\
\hline Bexar & $\bullet$ & $\bullet$ & $\bullet$ & $\bullet$ \\
\hline
\end{tabular}

Table 1: Paths deployed for IVE experiments.

We briefly describe for each of the four IVE events for which a disturbance was detected these parameters: the transmitter-receiver paths; the radio frequencies employed; a summary of the results; and sample power spectra versus time. The Ingot event for which no disturbance was detected took place so early in the morning that the ionosphere was in a nighttime condition; the acoustic waves would have dissipated before reaching the $300 \mathrm{~km}$ reflection altitude of our hf signals.

\section{Misty Echo}

For this tunnel event we employed transmitters at Tonopah Test Range operating at 3.70 and $3.75 \mathrm{MHz}$ and receivers at Indian Springs AFB. In the absence of ionosonde data of electron density content versus altitude, we must rely on models of electron density which predict that these frequencies reflected in the $\mathrm{E}$ layer of the ionosphere at an altitude of about $100 \mathrm{~km}$. Figure 2 shows the power spectra versus time for one set of data; although the signal to noise ratio for this data set was poor a disturbance beginning at $340 \mathrm{~s}$ after the explosion is evident. This delay corresponds to acoustic propagation to the $\mathrm{E}$ layer.

\section{Texarkana}

For this Area 7 event we employed transmitters at the EPA Farm operating at 2.90 and $3.30 \mathrm{MHz}$ and receivers at Well5e. Ionosonde data obtained at Well5e shows that the radio frequencies reflected in the $E$ layer of the ionosphere at an altitude of about $100 \mathrm{~km}$. Figure 3 shows the power spectra versus time for one set of data between 250 and $500 \mathrm{~s}$ after the event; a prolonged disturbance beginning at $335 \mathrm{~s}$ after the explosion is evident.

\section{Mineral Quarry}

For this tunnel event we employed transmitters at Tonopah Test Range and receivers at Indian Springs AFB. The radio frequencies were chosen to have reflected in the $E$ layer of the ionosphere at an altitude of about $100 \mathrm{~km}$. Figure 4 shows the power 
spectra versus time for one set of data; a disturbance beginning at $320 \mathrm{~s}$ after the explosion is evident.

\section{Bexar}

For this Area 19 event we employed all stations to obtain four reflection points ranging from almost directly overhead to $60 \mathrm{~km}$ distance. The operating frequencies were 3.82 and $3.92 \mathrm{MHz}$; ionosonde data obtained at Well5e shows that the radio frequencies reflected in the $E$ layer of the ionosphere at an altitude of about $100 \mathrm{~km}$. Figure 5 shows the power spectra versus time for one set of data; there is a disturbance beginning at $310 \mathrm{~s}$ after the explosion. 

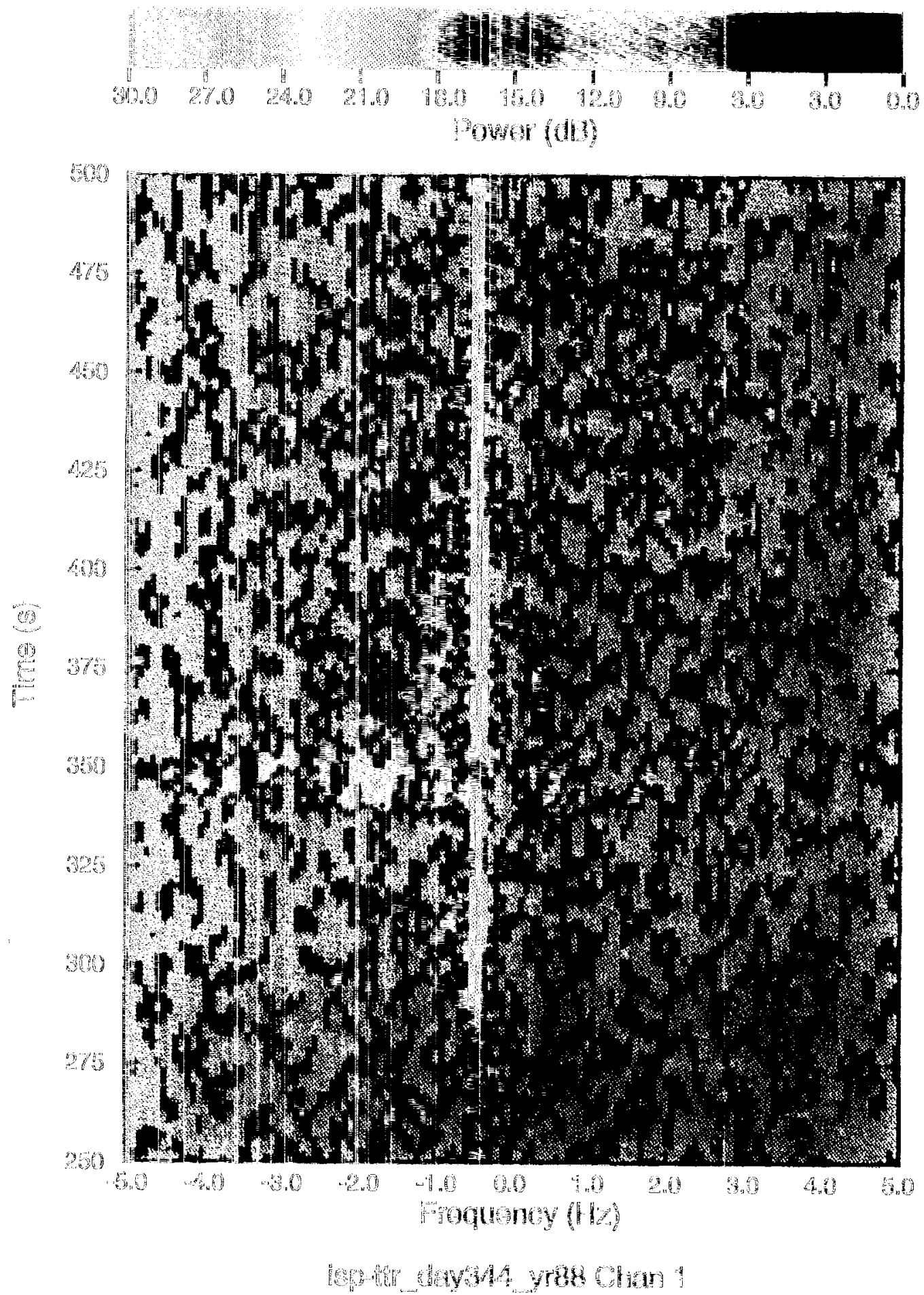

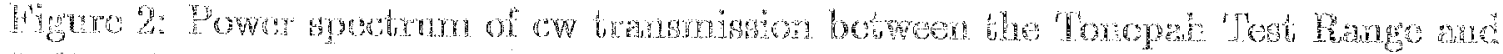

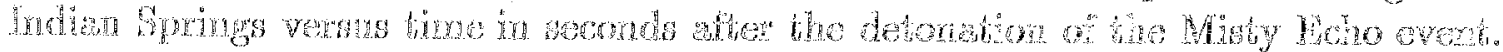

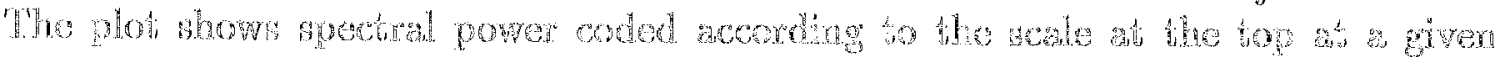

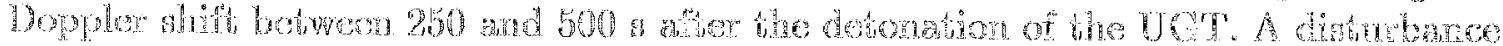

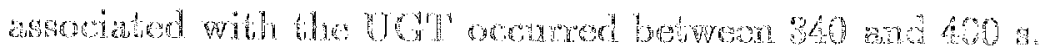



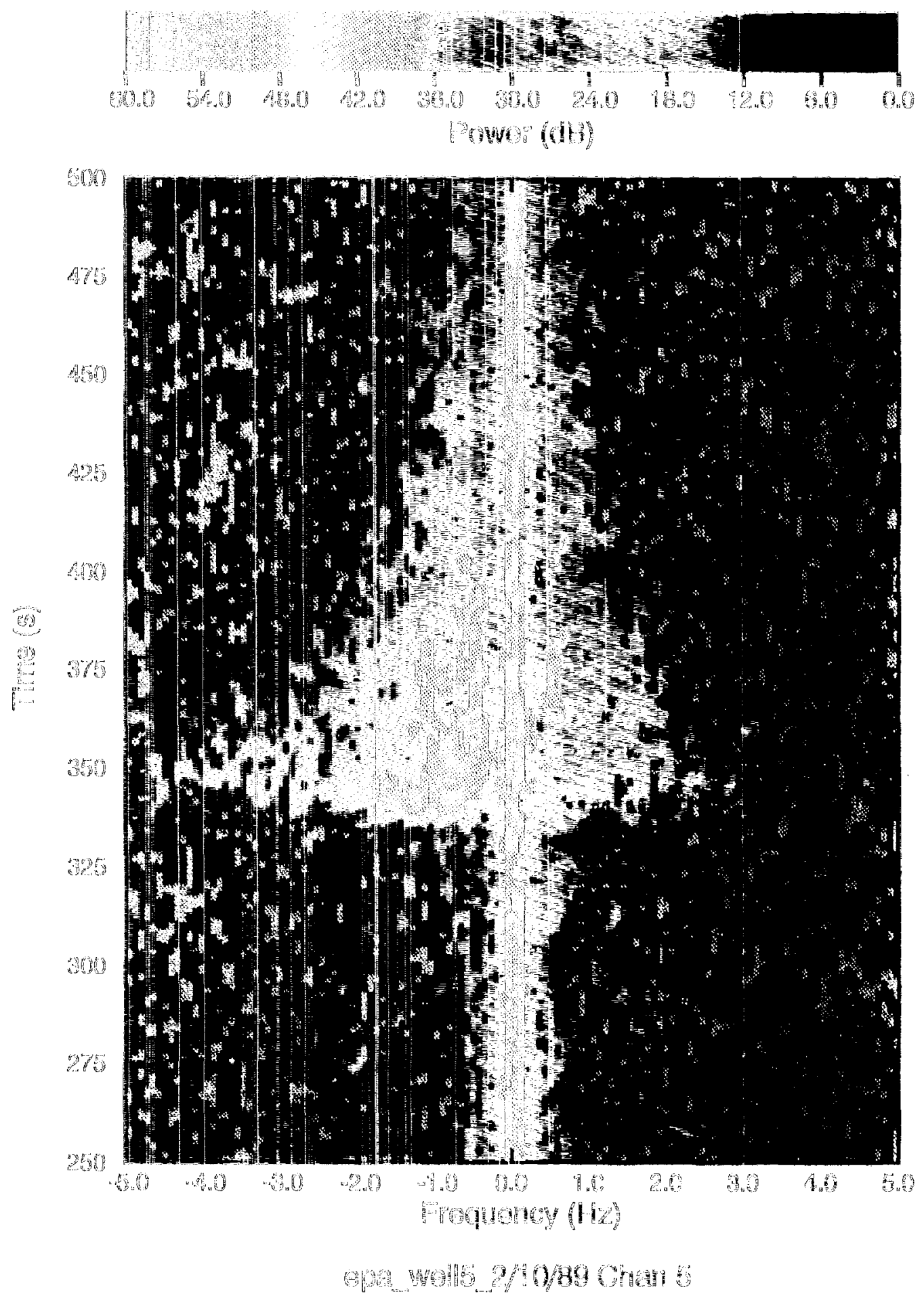

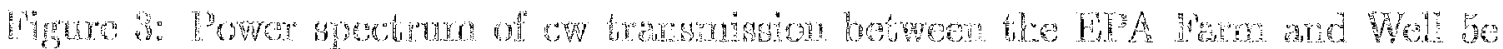

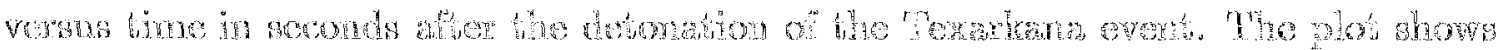

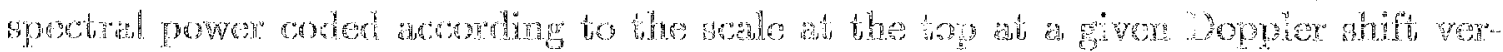

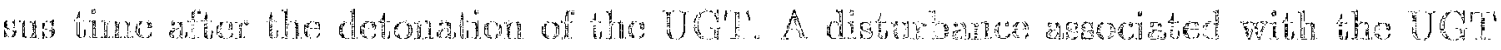

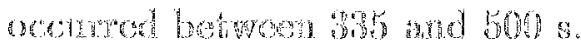



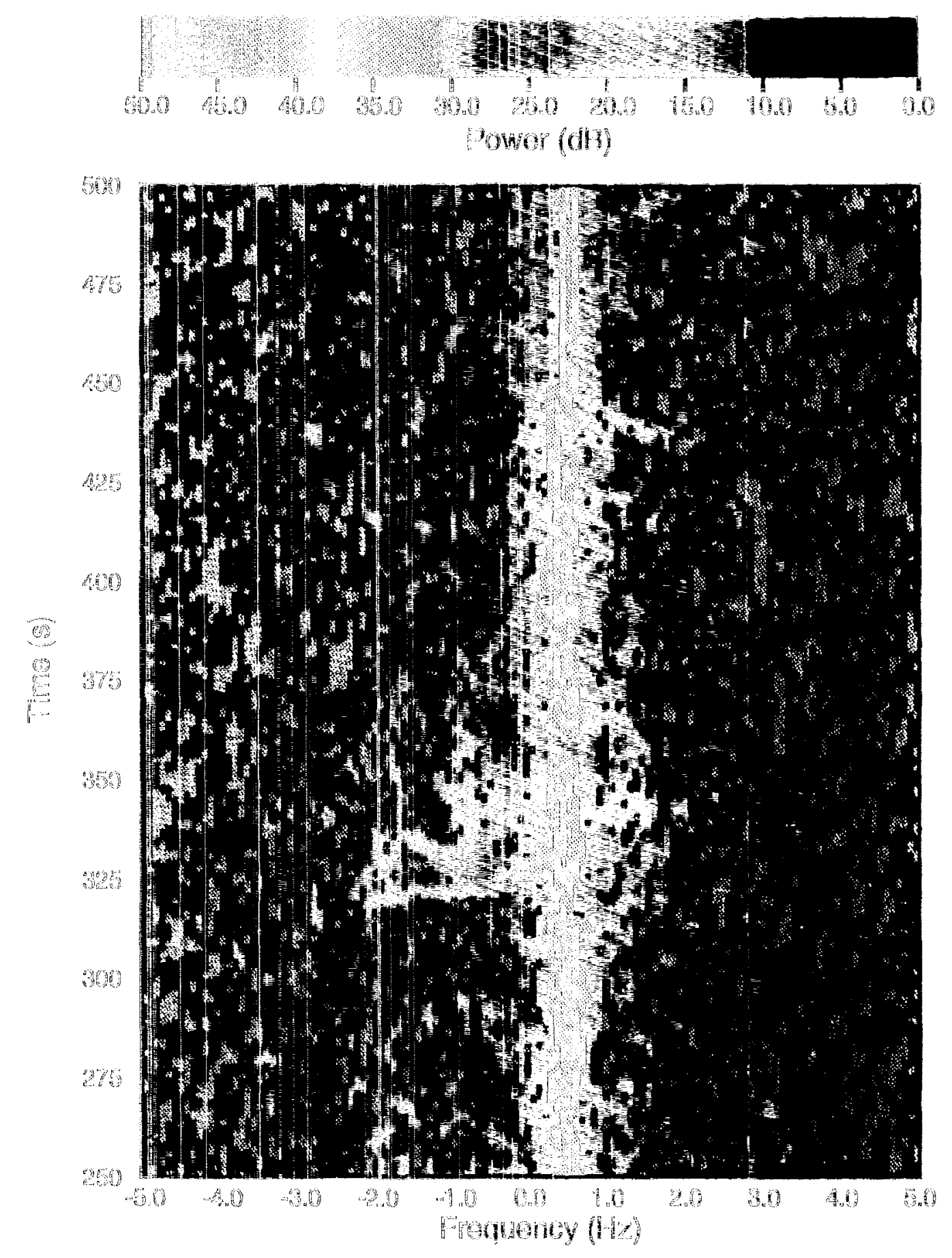

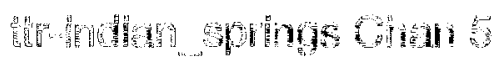

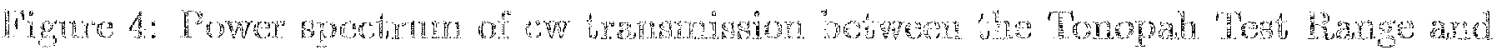

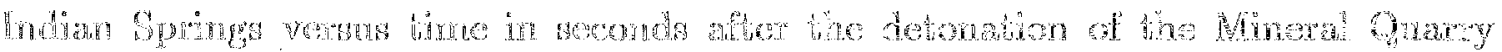

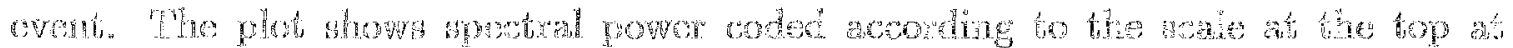

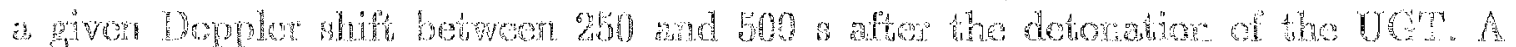

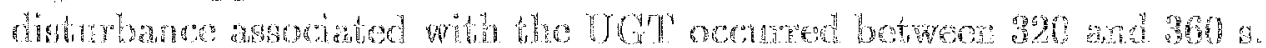



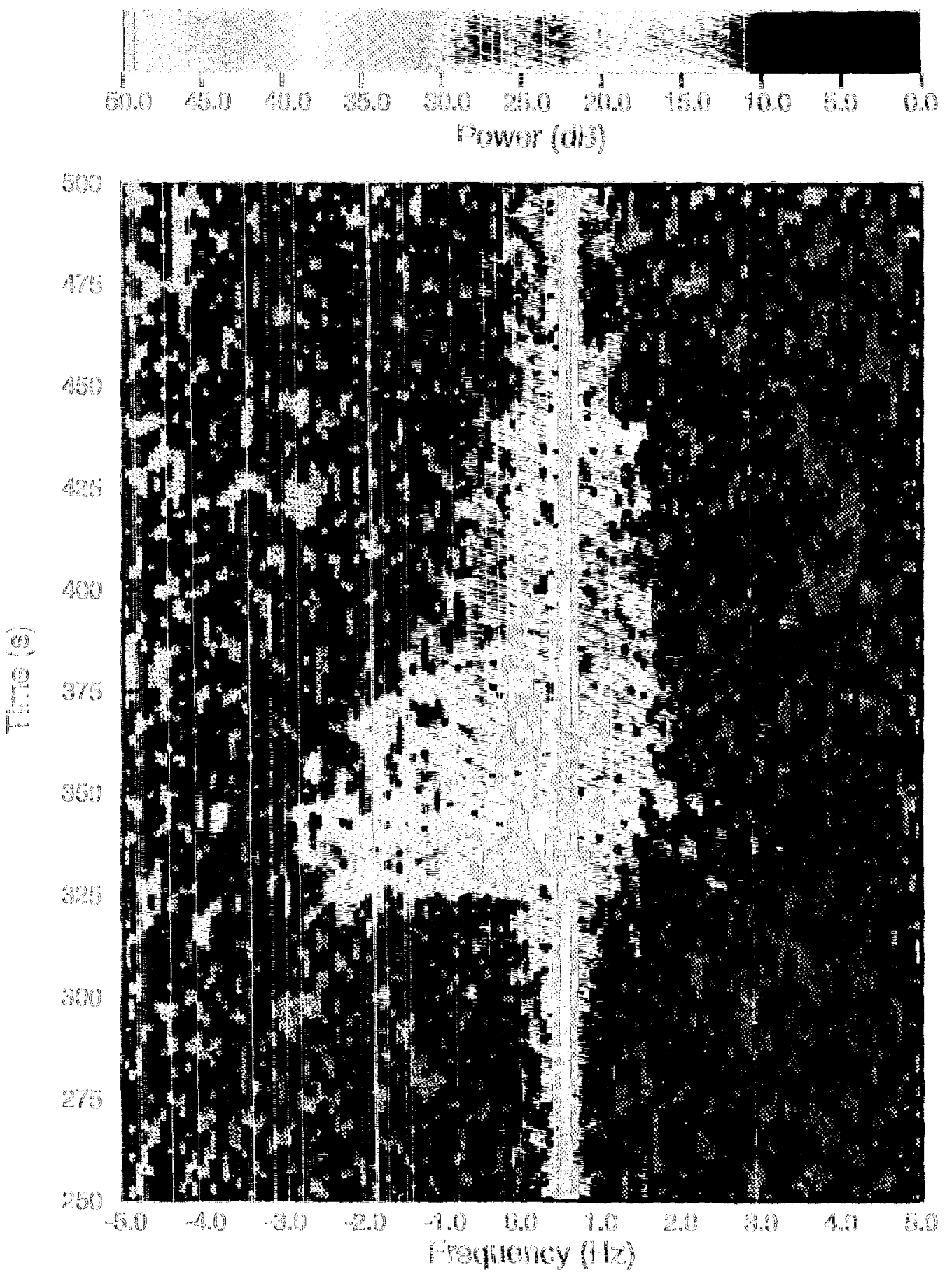

whas

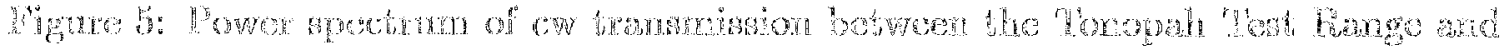

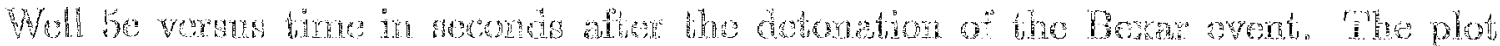

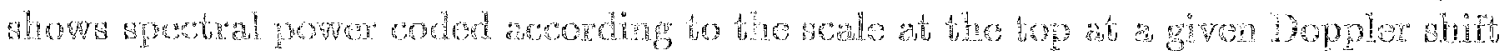

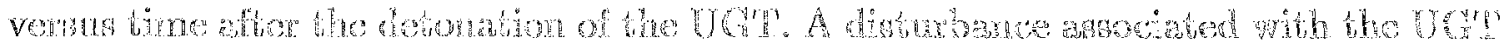

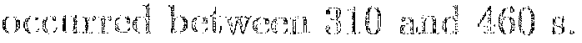




\section{Acknowledgement}

This work was performed under the auspices of the U. S. Department of Energy by Los Alamos National Laboratory under contract W-7405-ENG-36. Sandia National Laboratory provided the transmitter site at the Tonopah Test Range and the U. S. Air Force provided the receiver site at the Indian Springs AFB. 